\title{
Numerical Investigation of the Influence of Water Depth on Ship Resistance
}

\author{
Pritam Kumar Patel \\ M.Tech \\ Naval Architecture \& Ocean Engineering \\ Indian Maritime University
}

\author{
M Premchand \\ Scientist- C \\ National Ship Design \& Research Centre \\ Visakhapatnam
}

\begin{abstract}
Behavior of ship changes drastically, when it moves from deep to shallow water. In the recent years much research is going on the ship hydrodynamics for practical navigation problems in getting ships safely into existing harbors. Investigation of ship behavior in restricted water depth may helpful during sea trials in speed reduction criteria where larger depth is not available near the coastline. The proper estimation of ship resistance and squat is influence largely on the power calculation in the design stage. The present work describes the effect of shallow water on the ship resistance at different speed using Computational Fluid Dynamics (CFD) techniques. A comparison in the drag on the hull is illustrated between depth restriction and infinite depth water. This paper provides a wide introduction into the problems of modeling of the restricted water depth effects on the ship behavior, specifically resistance using CFD.
\end{abstract}

\section{General Terms}

Resistance Components, Computational Fluid Dynamics (CFD), Waves, Kelvin Wave Pattern, Sinkage and Trim, Under Keel Clearances (UKC).

\section{Keywords}

Shallow Water, Depth to Draft ratio, Numerical Grid, Depth Froude Number, Critical Speed, Domain, Volume of Fluid (VOF), Eulerian Multiphase, Turbulence, Karpov's Method.

\section{INTRODUCTION}

The resistance of a ship at a particular speed is the opposing forces acting on the ship by the fluid which oppose the forward motion. The opposing force by the fluid is due to the viscosity of the fluid and the pressure changes around the ship. The ship which is designed for operating in deep sea, it has to operate in shallow water also whenever it comes to port or harbour, gently it will have to encounter the shallow water effects.

When we are considering the shallow water it is the restriction in vertical direction. Potential flow around the ship hull changes when ship encounters shallow water. Due to less under keel clearance (UKC) the flow beneath the ship plays a major role in resistance. Flow velocity increases beneath the ship bottom in shallow water compared to deep water. Flow velocity increase because there is a narrow passage for flow between ship bottom and sea bed. As flow velocity increases there is a reduction in bottom pressure which is the source of upward buoyancy force. Thereafter increase in ship sinkage and trim may occur due to uneven reduction in pressure along the ship length. Ship resistance increases, so there is an involuntary reduction in the speed. As a result for same resistance, the value achieve at a lower speed in shallow water than in deep water. If one wants to maintain the same speed in shallow water as in deep water the ship may face grounding due to excess sinkage and trim. So there is a voluntary speed reduction in restricted water depth region.

It is felt that for shallow water the wave resistance is much more prominent than deep water. A ship moving in a shallowwater can shed so-called solitary waves when its speed is near the critical speed defined by Depth Froude number $F_{\mathrm{h}}=1.0$. These solitary waves travel a bit faster in front of the ship and cause ship oscillations in the vertical plane and drastic increase in wave resistance. There is a slow increase in wave resistance in Subcritical range, strong rise accompanied by oscillation of steeply increasing amplitude at the Trans-critical range and a slow drop in Super-critical range.

\section{SHALLOW WATER AND SHIP RESISTANCE}

\subsection{Shallow Water}

The hydrodynamic effect varies depends on the depth of the water. The forces on the ship go on increasing as the depth of water i.e. under keel clearances (UKC) reduces. The shallow water classification depends on the draft of the ship. It is mentioned as the ratio of draft to depth of the water (PIANC, 1992).

Table 1: Shallow Water Configuration

\begin{tabular}{|c|c|c|}
\hline Classification & Range & Effect on Ship \\
\hline Deep water & $\mathrm{h} / \mathrm{T}>3.0$ & No effect \\
\hline Medium deep & $1.5<\mathrm{h} / \mathrm{T}<3.0$ & Noticeable \\
\hline Shallow water & $1.2<\mathrm{h} / \mathrm{T}<1.5$ & Very significant \\
\hline Very shallow water & $\mathrm{h} / \mathrm{T}<1.2$ & Dominates motion \\
\hline
\end{tabular}

(" $\mathrm{h}$ " is depth of water, "T" is draft of ship )

\subsection{Ship Resistance}

The Resistance of a ship is the total force that opposes the forward motion of the ship at a constant speed in a straight line in still water. Alternately, the force required to tow a ship in calm water at a constant speed.

\subsubsection{Resistance Components}

The total Resistance of ship is composed of several causes and the phenomenons involved in that are complicated. For simplification, the total resistance is divided into several components. For a surface sea ship, the resistance is composed of air resistance and hydrodynamic resistance. Air resistance is caused by the ship which is exposed above the water surface and the hydrodynamic resistance is caused by 
the immersed (or wetted) surface of the ship. The hydrodynamic resistance is a result of viscosity of fluid.

The Resistance of the ship can be divided into two main components in two ways. In the first approach the total resistance of the ship is divided into viscous resistance and wave resistance. The second approach divides the total resistance into frictional resistance and pressure resistance. That part of the pressure resistance that is due to the viscosity is called viscous pressure resistance.

Due to excessively curved at the stern region of some ships, the flow separates from the hull surface and gives rise to eddies. Due to this flow separation and formation of eddies an additional resistance occurs called separation drag or eddy resistance.

An additional resistance results from the formation of wake. The resistance calculated from the change of momentum in the wake is called wake resistance.

The resistance determined from wave pattern is called wave making resistance. Other components of total resistance can be divided as wave breaking resistance, transom resistance, spray resistance etc.

\subsubsection{Shallow water Resistance}

It is difficult to separate finite-depth ship resistance into different additive components. But for simplicity, the shallow water ship resistance may be separated into parts due to friction and to wave-making as well. However, the value of both parts is distinct from that corresponding to deep water. When a ship moves in water of finite depth, the value of wave resistance varies both with $F_{\mathrm{n}}$ and the Depth Froude number $F_{\mathrm{h}}$.

In the light of the ship resistance characteristics of sidewise unrestricted water of finite depth, the ship speed generally may be divided into the following three different regions:

1. $F_{\mathrm{h}}<0.6$. This may be described as "subcritical speed range ", at which there is not much difference between shallow water resistance and deep water resistance.

2. $F_{\mathrm{h}}=0.6 \sim 1.2$. This is known as "near critical speed range" and includes critical speed, at which shallow water resistance is much greater than that in deep water. And shallow water resistance has maximum value at around critical speed with depth Froude number $F_{\mathrm{h}}=1.0$

3. $F_{\mathrm{h}}>1.2$. This can be called as "supercritical speed range", at which shallow water resistance drops significantly and rather smaller than that in deep water.

In general $F_{\mathrm{h}}<1$ and $F_{\mathrm{h}}>1$ is considered as sub-critical and super-critical speed respectively and critical speed with $F_{\mathrm{h}}=1$.

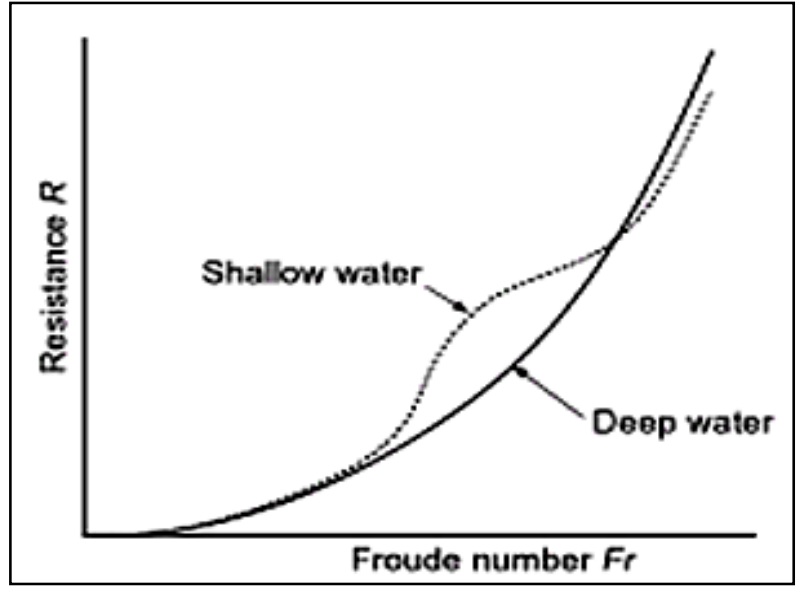

Figure 1 : Comparison of Deep and Shallow water Resistance

\section{COMPARISON OF WAVE PATTERN IN DEEP AND SHALLOW WATER}

\subsection{Kelvin Wave Pattern}

Lord Kelvin (1887) considered a single pressure point traveling in a straight line over the surface of the water, sending out waves which combine to form a characteristic pattern.

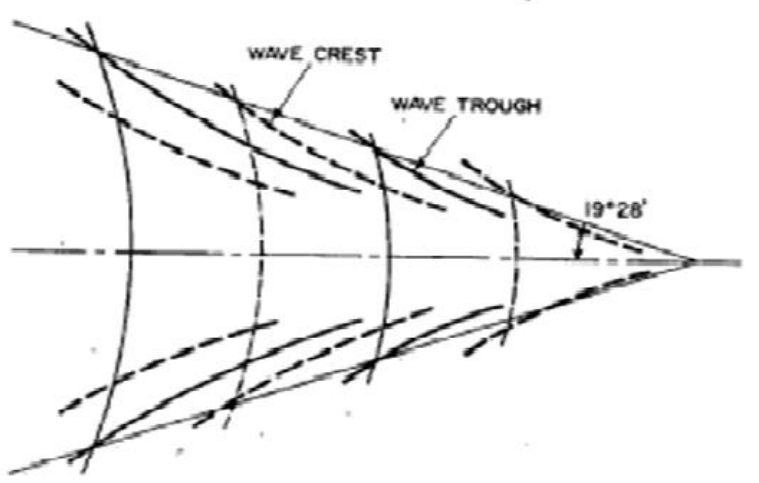

Figure 2: Kelvin Wave Pattern

A system of transverse waves, the heights of successive crests diminish when transverse wave go afterwards with respect to the pressure point. A series of divergent waves, the whole pattern is roughly contained within two straight lines, which start from the pressure point and make angles of $19^{\circ} 28^{\prime}$ on each side of the line of the motion.

\subsection{Shallow Water Wave Pattern}

The wave pattern in shallow water depends on the speed of the ship i.e. sub-critical, critical or super-critical speed. (See sec 2.2.2). In sub-critical speed region i.e. $F_{\mathrm{h}}$ below 1 there is prominent visible of transverse and divergent waves. When the speed comes to critical speed with $F_{\mathrm{h}}=1$ the waves approaches perpendicular to the path of the ship. In the supercritical speed region the divergent waves comes back to the path of the ship with some angle, but in this case no transverse waves are visible [1]. 


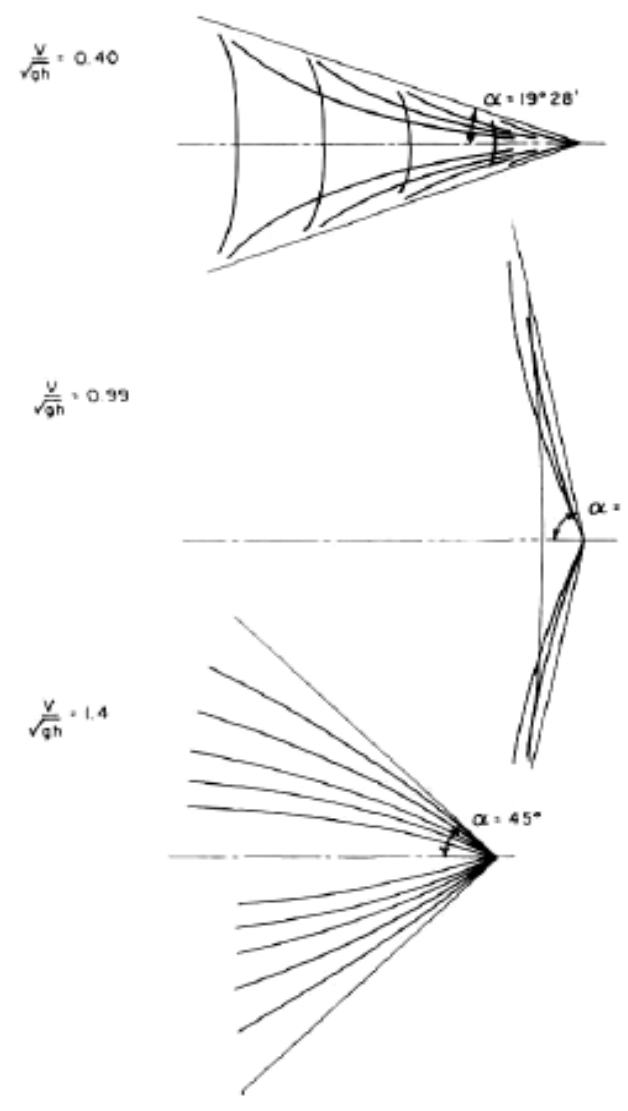

Figure 3: Shallow water waves for different speed

\section{NUMERICAL SIMULATION}

The CFD analysis is carried out through a commercial tool Star CCM+ for deep as well as shallow water.

\subsection{Computational assumptions}

Computations were performed for two cases of water depth i.e. deep water $(\mathrm{h} / \mathrm{T}=25.2)$ and shallow water $(\mathrm{h} / \mathrm{T}=1.5)$.

The following assumptions were used in simulation modelling:

- Linear motion with constant speed,

- Computation with free surface,

- Surface without waves and current,

- No width restriction is considered in both the cases

- Ship is considered without propeller influence,

- Flat sea bed bottom without natural irregularities,

- No dynamic mesh,

- Speed ranges from sub-critical speed to supercritical speed for shallow water cases and three speeds for deep water case with low, high and one intermediate speed.

\subsection{Simulation Overview}

- Importing Geometry

- Creating Virtual Towing Tank(Domain)

- Assigning Parts

- Generation of volume mesh

- Setting Mesh Parameters

- Volumetric Refinement where it is necessary

- $\quad$ Setting the Physical parameters

- Assigning Boundary Condition

- $\quad$ Setting Solver Parameters

- Running Simulation
- $\quad$ Result and Analysis

\subsection{Hull Geometry}

The computations were performed for DTMB-5415 hull for a scale ratio of 24.830. Full scale ship not exists (SIMMAN, 2014) [20].

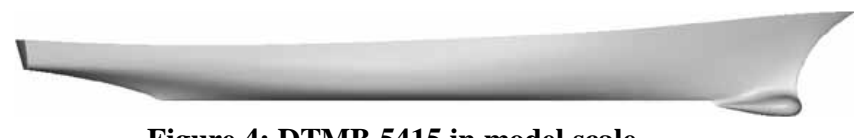

Figure 4: DTMB 5415 in model scale

Table 2 : Hull Particulars

\begin{tabular}{|c|c|c|c|}
\hline Description & $\begin{array}{c}\text { Representation } \\
\text { (unit) }\end{array}$ & Ship & Model \\
\hline Scale factor & $\lambda$ & - & 24.830 \\
\hline $\begin{array}{c}\text { Length bet. } \\
\text { perpendicular }\end{array}$ & LPP (m) & 142 & 5.72 \\
\hline $\begin{array}{c}\text { Length of } \\
\text { waterline }\end{array}$ & LWL (m) & 142 & 5.72 \\
\hline Breadth & $\mathrm{B}(\mathrm{m})$ & 18.9 & 0.76 \\
\hline Draft & $\mathrm{T}(\mathrm{m})$ & 6.16 & 0.248 \\
\hline $\begin{array}{c}\text { Displacement } \\
\text { Volume }\end{array}$ & $\nabla(\mathrm{t})$ & 8636.0 & 0.549 \\
\hline Wetted Surface & $\mathrm{S}\left(\mathrm{m}^{3}\right)$ & 8425.4 & 0.549 \\
\hline
\end{tabular}

\subsection{Virtual Towing Tank (Domain)}

Domain is the region geometrically defined where the analyses were performed. The domain dimensions for both deep and shallow water cases have same dimensions in the horizontal plane but below (distance between ship bottom and the lower plane of the domain) the ship it depends on the depth restriction. Due to port-starboard symmetry only half of the domain is modeled and symmetry condition assigned.

- Shallow water :

- One ship length Forward

- Two ship length Side

- Four ship length Aft

- Below according to depth restriction $(\mathrm{h} / \mathrm{T}=1.5)$

- Deep water :

$$
\begin{array}{ll}
\text { - } & \text { One ship length Forward } \\
\text { - } & \text { Two ship length Side } \\
\text { - } & \text { Four ship length Aft } \\
\text { - } & \text { One ship length Below }
\end{array}
$$

\subsection{Numerical Grids}

For each water depth a numerical grid was generated. In order to achieve the accurate resistance predictions hexahedral mesh was used. To capture the exact flow behavior near the walls of wetted surface prism layers were used. In order to refine the computational mesh where it is necessary volumetric controls with particular shapes were created. The accuracy of a CFD solution is governed by the number of cells in the grid. Optimal meshes are often non-uniform: finer in areas where 
large variations occur from point to point and coarser in regions with relatively little change. For that a fine mesh in the stern and bow region were created where flow disturbances occurs. To capture the flow around the hull near the free surface a finer mesh was created in the free surface region i.e. draft region.

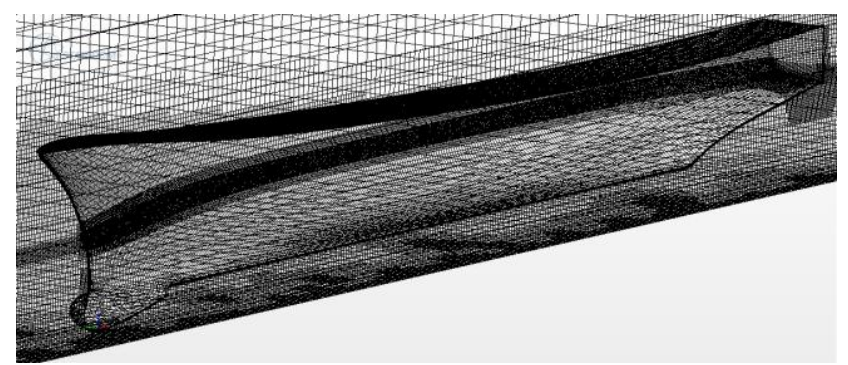

Figure 5: A part of mesh showing free surface refinement with domain

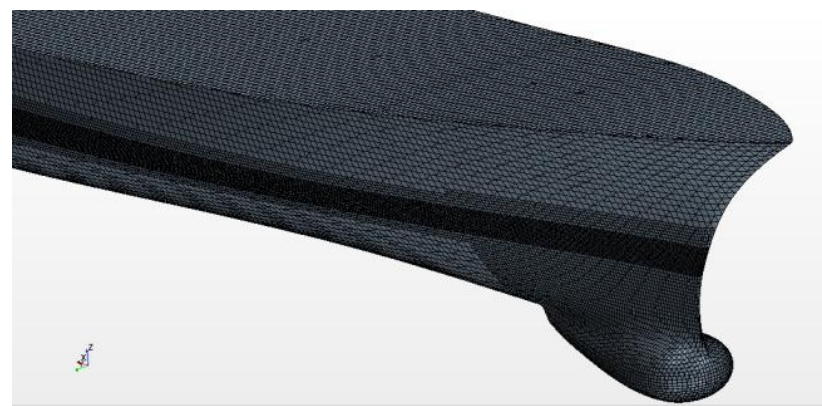

Figure 6: A part of ship mesh with refinement

In total, this grid contains 4,46,041 cells for deep water case. For shallow water, with water depth being 1.5 times the ship draft, the generated grids contains 7,79,269 cells.

\subsection{Boundary Conditions}

The following boundary conditions were applied for analysis using Star CCM+.

Table 3 : Boundary Conditions

\begin{tabular}{|c|c|c|}
\hline Parts & Shallow Water & Deep Water \\
\hline Inlet & Velocity Inlet & Velocity Inlet \\
\hline Outlet & Pressure Outlet & Pressure Outlet \\
\hline Side & No-Slip Wall & No-Slip Wall \\
\hline Hull & No-Slip Wall & No-Slip Wall \\
\hline Symmetry & Symmetry Plane & Symmetry Plane \\
\hline Top & No-Slip Wall & \begin{tabular}{c} 
No-Slip Wall \\
\hline Bottom
\end{tabular} \\
\hline
\end{tabular}

In the case of restricted water depth, there is effect of sea bed on hydrodynamic forces of ship. For that sea bed effect there should be a relative velocity between ship and bottom. The bottom moves with a velocity equal to speed of ship.

\subsection{Physical and Numerical Setup}

Resistance simulation is transient multiphase problem and analysis is carried out in turbulence and viscous condition.
Setting this simulation involves:

- Initial conditions

- Boundary conditions

- VOF multiphase

- VOF Waves and wave damping

- Transient numerical parameters

Some of the physical models selected for the analysis were Implicit unsteady, Eulerian Multiphase, Volume of Fluid, Turbulent, K-Omega Turbulence, and VOF Waves. The free surface is modelled using the Volume of Fluid (VOF) method. The initial conditions were set according to the problem description. VOF multiphase model created in Eulerian phase for water and air. As the analysis was carried out in calm water the VOF Waves defined as a flat VOF Waves. The initial condition for pressure, velocity and volume fraction were set.

\subsubsection{Damping Wave Reflection}

Wave reflection can occur during a flow resistance simulation. These wave reflections must avoid, because they interact with the true wave field and can lead to invalid results [16]. There are two sources for wave reflection: Wave reflections from boundaries and Wave reflections due to abrupt mesh transitions. In STAR-CCM+ VOF Wave damping functionality provides a remedy for the wave reflection from boundaries.

\section{POST PROCESSOR}

This is the process of extraction of desired result from the simulation setup. Versatile data visualization tools such as Domain geometry and grid display, Vector plots, Line and shaded contour plots, 2D and 3D surface plots etc helps in Visualizing the propagation of Free Water Surface, Visualizing the Wave Pattern, Monitoring and Plotting Resistance Data etc.

The field method draws upon the solution of the NavierStokes equations which describe the dynamics of a viscous and incompressible flow. Forces acting upon the ship hull are obtained by integrating the pressure and shear stresses over the ship's surface allowing for a separate analysis of pressure and friction resistance. To arrive at a prediction of the total resistance, friction resistance is found from the ITTC-1957 frictional correlation line (ITTC, 2002) taking into account local Reynolds numbers at each panel along the ship hull.

The analyses were carried out for the following velocities (see Table 4). For shallow water speeds were taken covering the three regions of velocities and for deep water three speeds were taken including the service speed. 
Table 4 : Velocity regions

\begin{tabular}{|c|c|c|c|c|}
\hline \multicolumn{3}{|c|}{ Shallow Water } & \multicolumn{2}{c|}{ Deep Water } \\
\hline Velocity $(\mathrm{m} / \mathrm{s})$ & $F h$ & Region & Velocity $(\mathrm{m} / \mathrm{s})$ & $F n$ \\
\hline 1.124 & 0.588 & Sub-critical & 1.124 & 0.15 \\
\hline 1.648 & 0.862 & Sub-critical & 2.696 & 0.28 \\
\hline 1.91 & 0.999 & Critical & 3.071 & 0.41 \\
\hline 2.097 & 1.097 & Super-critical & - & - \\
\hline 2.696 & 1.411 & Super-critical & - & - \\
\hline
\end{tabular}

\section{SHALLOW WATER RESISTANCE PREDICTION}

Resistance of water to ship moving in shallow water had been studied by Karpov $(1945,1946)$ who developed an approximate method of practical calculations [6]. This method is based on replacing the actual speed of the ship with notional speeds which are taken different in calculating residual resistance and frictional resistance.

Resistance to ship moving in shallow water of depth $h$ is:

$$
R=0.5\left(C_{F 0} v_{1}^{2}+C_{R} v_{2}^{2}\right) \rho S
$$

Where, $C_{F 0}$ - frictional resistance coefficient

$C_{R}-$ residual resistance coefficient

$\rho$ - water density: $S$ - wetted surface area

$v_{1}$ and $v_{2}$ - notional speeds

$v_{1}=v_{0} / \alpha^{*}$ and $v_{2}=v_{0} / \alpha^{* *}$

$\alpha^{*} \& \alpha^{* *}$ - coefficient obtained from the Karpov's graphs (fig 7) as functions of water depth to draft ratio and Froude number by water depth $F_{h}$.
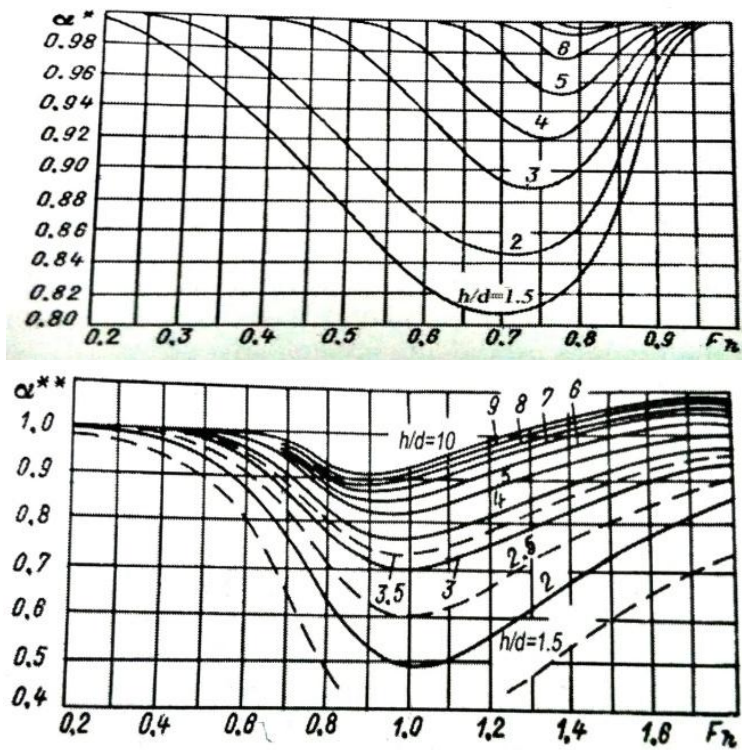

Figure 7: Karpov's graph for coefficients $\alpha^{*} \& \alpha^{* *}$ in determining the water resistance in shallow water

Frictional resistance coefficient $C_{F 0}$ is determined by traditional methods as a function of Reynolds number calculated via velocity $v_{1}=v_{0} / \alpha^{*}$. Residual resistance $C_{R}$ is determined as a function of Froude number for deep water

\section{RESULT AND DISCUSSION}

The simulations were performed for the above mentioned speeds and the corresponding drags were taken. The changes in wave pattern in shallow water according to speed i.e. subcritical, critical and super-critical speed are noticed. The pressure and velocity change of the flow between the hull surface and bottom of the tank is noticed and shown.

\subsection{Wave Pattern Created by shallow water at different speed regions}

The wave pattern shown here are at three different speeds in shallow water that discussed in sec 3.2 and shown in Fig 3.

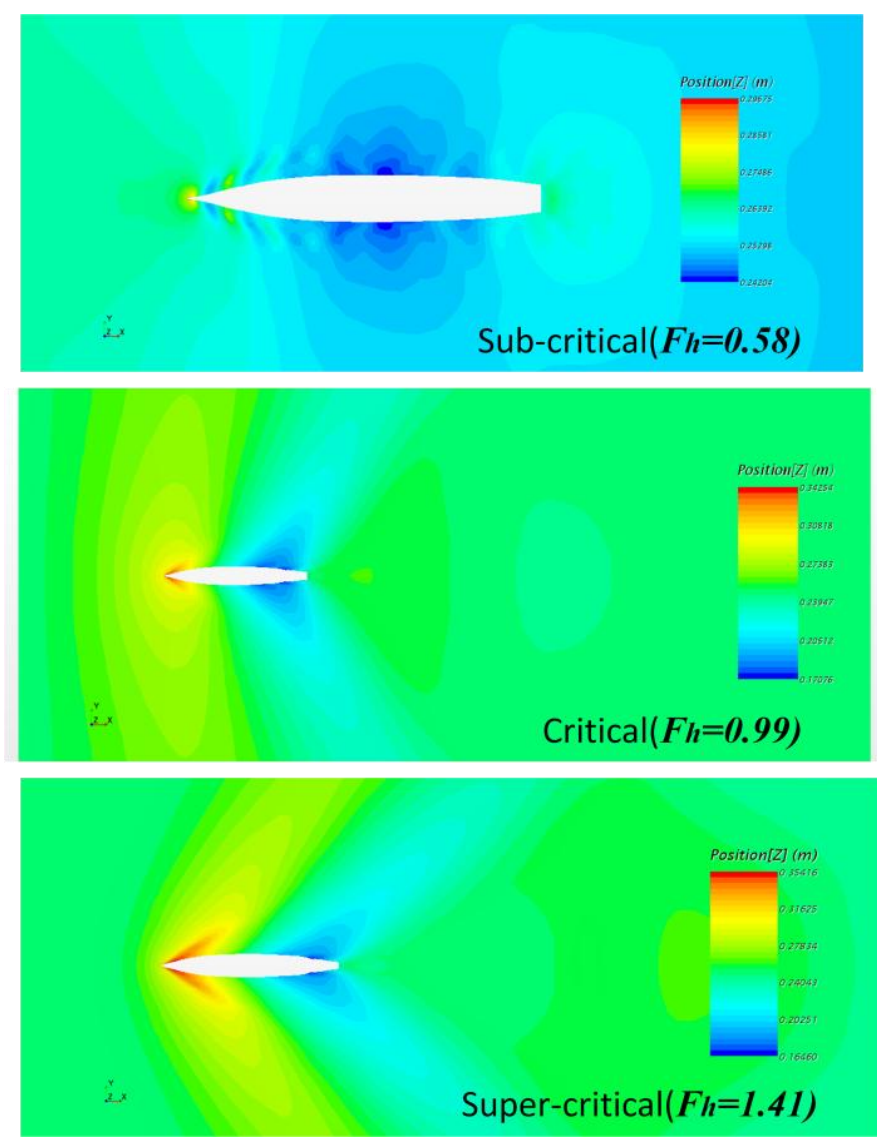

Figure 8: Wave pattern at different speeds in shallow water 


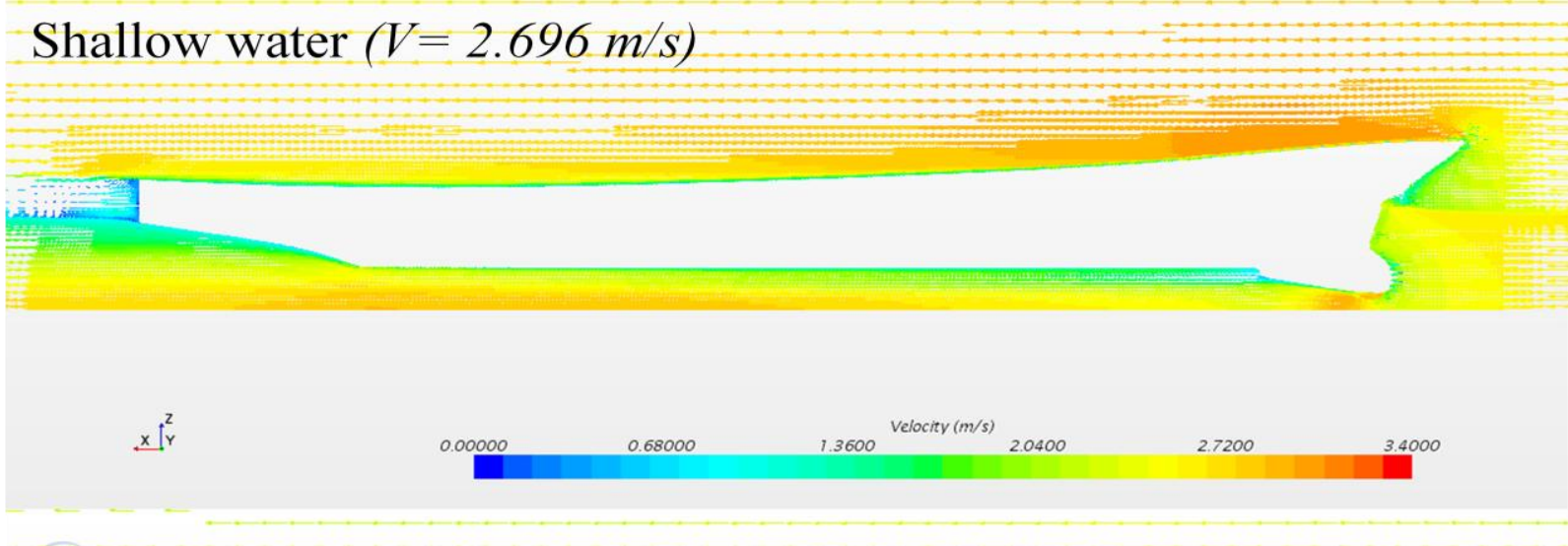

\section{Deep water $(V=2.696 \mathrm{~m} / \mathrm{s})$}
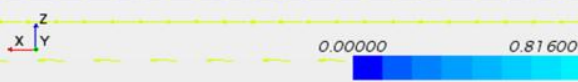

Velocity $(\mathrm{m} / \mathrm{s})$

$1.6320 \quad 2.4480$

3.2640 4.0800

Figure 9: Comparison of under keel velocity of flow at deep and shallow water at same speed $(\mathrm{V}=2.696 \mathrm{~m} / \mathrm{s})$

\subsection{Under keel flow velocity}

The velocity of flow under the keel changes when the vessel moves from deep to shallow water. In the above fig. the changes in flow velocity is clearly shown. This change in velocity of flow is due to the effect of the bottom of the tank which is the sea bed in the real ocean. In shallow water the velocity of flow under the keel increases so there is a significant drop in pressure. As a result buoyancy, which is the upward force to the ship, decreases. So the ship sinks further from its original draft. As a result there is a increase in resistance.

\subsection{Resistance Comparison}

First the analyses were performed for deep water with three speeds and compared with experimental values and the results obtained were satisfactory. For comparison with shallow water resistance directly experimental values were taken.

Table 5 : Deep water resistance

\begin{tabular}{|c|c|c|c|}
\hline $\begin{array}{c}\text { Velocity } \\
(\mathbf{m} / \mathbf{s})\end{array}$ & $\begin{array}{c}\text { RT }(\mathbf{N}) \\
\text { (Analysis) }\end{array}$ & $\begin{array}{c}\text { RT (N) } \\
\text { (Expt.) }\end{array}$ & $\begin{array}{c}\text { Percentage } \\
\text { Variation }\end{array}$ \\
\hline 1.124 & 12.78 & 12.11 & 5.24 \\
\hline 2.696 & 90.44 & 88.28 & 2.38 \\
\hline 3.071 & 151.52 & 152.70 & $-\mathbf{0 . 7 8}$ \\
\hline
\end{tabular}

Table 6 : Shallow water resistance

\begin{tabular}{|c|c|c|c|}
\hline $\begin{array}{c}\text { Velocity } \\
(\mathrm{m} / \mathrm{s})\end{array}$ & Fh & $\begin{array}{c}\text { RT }(\mathbf{N}) \\
(\text { Karpov })\end{array}$ & $\begin{array}{c}\text { RT }(\mathbf{N}) \\
\text { (Analysis) }\end{array}$ \\
\hline 1.124 & 0.588 & 17.65 & 17.87 \\
\hline 1.648 & 0.862 & 59.23 & 63.34 \\
\hline 1.91 & 0.999 & 106.2 & 110.08 \\
\hline 2.097 & 1.097 & - & 168.07 \\
\hline 2.696 & 1.411 & - & 239.71 \\
\hline
\end{tabular}

The shallow water resistances were predicted using Karpov's method is compared with analysis result which shows a better agreement up to critical speed. Above critical speed i.e. in the super-critical speed region Karpov's method is not giving proper estimation of shallow water resistance. 


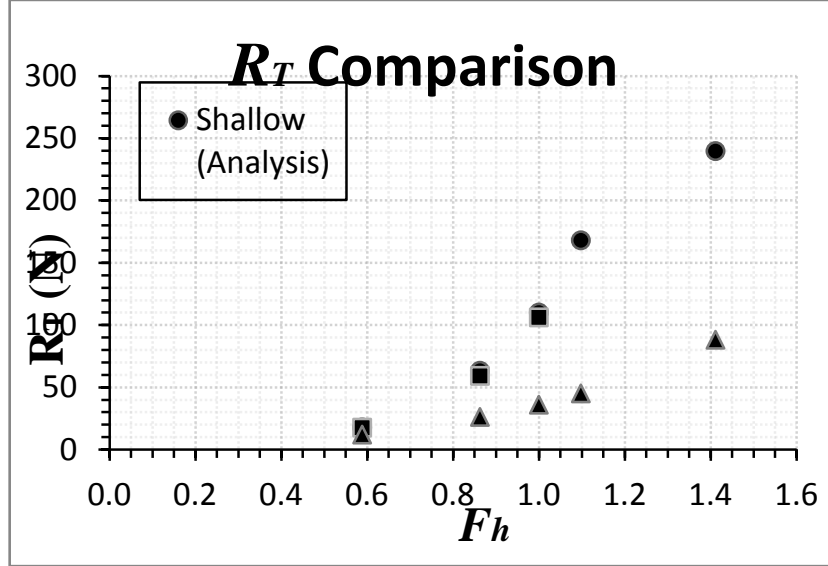

Figure 10: Comparison of deep and shallow water resistance

The increase in resistance in shallow water as compared to deep water is shown below.

Table 7 : Increase in Resistance in shallow water

\begin{tabular}{|c|c|c|c|}
\hline $\begin{array}{c}\text { Velocity } \\
(\mathrm{m} / \mathbf{s})\end{array}$ & $\begin{array}{c}\text { RT }(\mathbf{N}) \\
\text { (Deep } \\
\text { water) }\end{array}$ & $\begin{array}{c}\text { RT }(\mathbf{N}) \\
\text { (Shallow } \\
\text { water) }\end{array}$ & $\begin{array}{c}\text { Percentage } \\
\text { Increase in } \\
\text { RT }\end{array}$ \\
\hline 1.124 & 12.11 & 17.87 & 47.51 \\
\hline 1.648 & 26.27 & 63.34 & 141.12 \\
\hline 1.91 & 36.12 & 110.08 & 204.75 \\
\hline 2.097 & 45.17 & 168.07 & 272.08 \\
\hline 2.696 & 88.28 & 239.71 & 171.53 \\
\hline
\end{tabular}

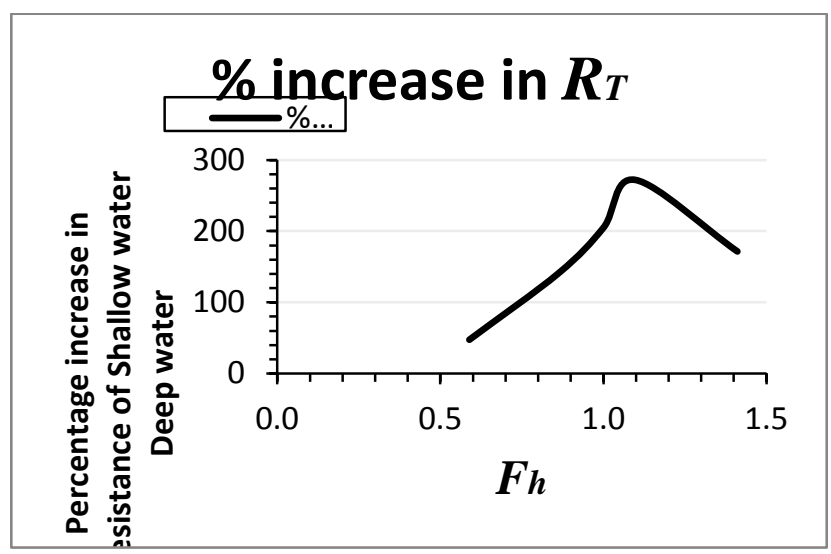

Figure 11: Percentage increase in shallow water resistance compared to deep water resistance

It observed that there is a noticeable change in resistance between both the water depths (i.e. Deep and Shallow water). The resistance increase is high near the critical speed region and it goes on decreasing significantly as the speed of ship crosses the critical speed.

\section{CONCLUSION}

The resistance predicted at shallow water $(\mathrm{h} / \mathrm{T}=1.5)$ by empirical method (Karpov's method) and by using CFD analysis shows a better agreement between both. The resistance in shallow water can be calculated up to critical speed with a better accuracy using this method.

The increase in resistance in shallow water as compared to deep water at same speed is significantly noticeable. The percentage increase in resistance goes on increasing as the Depth Froude number, $F_{\mathrm{h}}$ increases. The highest increase in resistance in shallow water compared to deep water is observed near the critical speed region i.e. $F_{\mathrm{h}}=0.6 \sim 1.2$, and it gradually decreases as the speed increases further. Resistance in shallow water will be less than deep water at a certain speed if the ship will exceed the critical speed region, but maintaining ships' speed above critical speed in shallow water is most dangerous, as there is most probable chance of grounding of the ship due to more sinkage and trim.

The wave pattern obtained from analysis (fig 8) in shallow water at different speed region gives a fair correlation with theoretical prediction (Havelock, 1908) as shown in fig 3. In sub-critical speed $\left(F_{\mathrm{h}}=0.58\right)$ the wave pattern is proper with Kelvin wave pattern. At critical speed the waves diverges from ships' centre line by making an approximate angle of 90 degree. As the speed increase to super-critical speed $\left(F_{\mathrm{h}}=0.41\right)$ the diverging waves again comes back to path of ship with some angle (as in critical speed waves were making approximately 90 degree to path of ship).

The velocity of flow between the keel and bottom of the tank, shown in fig 9 shows a better understanding of sinkage and trim of ship in shallow water. Due to increase in flow under the keel there is a reduction in pressure in that region, as a result buoyancy decreases and results in sinkage and trim. As the sinkage of ship occurs, wetted surface area increases, as a result viscous drag increases.

\section{REFERENCES}

[1] Edward V. Lewis, Editor, Principle of Naval Architecture, Volume II, SNAME.

[2] T.Jiang (Mercator University, Germany), Investigation of Waves Generated by Ships in Shallow Water.

[3] Zhao Lian-en, Optimal Ship Forms for Minimum Total Resistance in Shallow Water, Hamburg, Technische Universität Hamburg-Harburg, 1984.

[4] Hoyte C. Raven, A computational study of shallow-water effects on ship viscous resistance, Maritime Research Institute Netherlands.

[5] PIANC, Capability of ship manoeuvring simulation models for approach channels and fairways in harbours, 1992.

[6] Anatoly Lyakhovitsky, Shallow water and Supercritical Ships, Backbone Publishing Company, USA.

[7] Senthil Prakash M.N, Binod Chandra, Numerical Estimation of Shallow water resistance of a river sea ship using CFD, 2013.

[8] John D. Anderson. Jr. Computational Fluid Dynamics, Mc Graw Hill, 1995

[9] Leo Lazauskas, Resistance and Squat of Surface Combatant DTMB Model 5415: Experiments and Predictions, Cyberiad, 2009. 
[10] A. Olivieri, F. Pistani, A. Avanzini, F.Stern and R. Penna, Towing tank experiments of resistance, sinkage and trim, INSEAN, IIHR Technical Report No. 421, 2001.

[11] H K Versteeg and W Malalasekera, An Introduction to Computational Fluid Dynamics, Pearson Education Limited, England, 1995.

[12] H. Lackenby, M.Sc, M.R.I.N.A, The Effect of Shallow water on Ship Speed, September 1963.

[13] Zhao Lian-en, Optimal Ship Forms for Minimum Total Resistance in Shallow Water, Hamburg, Technische Universität Hamburg-Harburg, 1984.

[14] J. Holtrop and G.G.J. Mennen, An approximate power prediction method.

[15] CD-adapco, CFD Basics, Americas Agency Training Document.
[16] Star CCM+, Tutorial manual, Motion.

[17] Hoyte C. Raven, A computational study of shallowwater effects on ship viscous resistance, Maritime Research Institute Netherlands, 2012.

[18] Tim Gourlay, Flow Beneath a Ship at Small Underkeel Clearance, Centre for Marine Science and Technology, Western Australia, 2006

[19] Metin Taylan, Behavior of Ships in Shallow Water and Restricted waters, I.T.U, Turkey, 2001.

[20] SIMMAN, 2014, FORCE Technology, US Navy Combatant, Description, Geometry and Conditions.

[21] Y.M. Ahmed, Numerical simulation for the free surface flow around a complex ship hull form at different Froude numbers, Alexandria University, Alexandria, Egypt, 2011. 